\title{
Assessing Maintenance Time, Cost and Uncertainty for Offshore Production Facilities in Arctic Environment
}

\author{
Eirik Homlong ${ }^{1}$, Dina Kayrbekova ${ }^{3}$, Sukhvir Singh Panesar ${ }^{2}$, and Tore Markeset ${ }^{3}$ \\ ${ }^{1}$ Bergen, Norway \\ eirikhomlong@netcom.no \\ ${ }^{2}$ Apply Sørco, Stavanger, Norway \\ sukhvir.singh. panesar@applysorco.no \\ ${ }^{3}$ University of Stavanger, N-4036 Stavanger, Norway \\ \{dina.kayrbekova, tore.markeset\} @uis.no
}

\begin{abstract}
Many of the oil and gas fields on the Norwegian Continental Shelf are entering their tail-end phase of the production life cycle, and the production in temperate areas is slowly declining. Thus, the oil and gas industry looks northwards, and this trend can be seen in all countries bordering the Arctic. Arctic conditions in the form of climate, darkness, ice, remoteness from infrastructure, etc. will cause different and bigger strains on the human factor of the working personnel and machinery than can be seen in more temperate areas. Furthermore, the fact that less data exists - in the form of both statistics and experience of the operation and maintenance strategies to be executed in the Arctic areas - poses additional challenges for the design of offshore production facilities to be used in the less familiar environment of the Arctic. This paper introduces and discusses a method for maintenance cost and time assessments and their uncertainty, using the Monte Carlo simulation method. The method is to be employed when designing for operation and maintenance in Arctic conditions of offshore production facilities. The proposed method can enable a decision maker to assess and adjust maintenance time and cost data more realistically.
\end{abstract}

Keywords: Operation, Maintenance, Offshore production facility, Arctic conditions, Cost assessment, Monte Carlo Simulation method.

\section{$1 \quad$ Introduction}

With oil and gas production reaching its tail end on many fields on the Norwegian Continental Shelf (NCS), the industry is looking towards the Arctic to start exploration and production. It is estimated that as much as $14 \%$ of the world's remaining oil and gas reserves are found in Arctic areas, most of these offshore [1]. The harsh Arctic conditions concerning climate, lack of infrastructure and the long distances to shore generates challenges concerning the operation and maintenance of offshore production installations in Arctic areas. Maintenance expenses contribute to a large percentage of the operating cost for an offshore production installation. Continuous preventive and corrective maintenance, together with inspections etc., is important to keep the regularity high and the risks low for the installation. An increasing need for energy, a decreasing amount of resources in temperate areas, new technology, large 
amounts of offshore resources in Arctic areas and melting ice caps in the Arctic Ocean make this an important location for future developments.

The challenges for offshore oil and gas production in the Arctic can be greater than for oilfields in more temperate areas. In the Arctic areas the climate is hard with strong winds, low temperatures and long periods of darkness, resulting in greater and different strains on machinery, structure and personnel, and this complicates resupplying and maintenance [2], [3]. Due to the remote location and long distances, the infrastructure is less developed; large areas are scarcely populated and it is far from the suppliers of spare parts and competence [4], [5]. All of these factors are further complicating the operation and maintenance of an installation operating in the Arctic.

Another important factor for the Arctic offshore areas is the lack of statistical data. Large areas lack statistical data on metocean factors, sea ice, icing, currents and on equipment failure rates and failure modes. Experience from the Norwegian Continental Shelf together with data gathered in the OREDA database [6] can give us a good basis for much equipment performance and failure data, but the information is not good enough to use directly when moving production into the Arctic because it does not take into account the differences in operating conditions. In general, quantitative data from the Arctic is hard to obtain due to the small amount of industry and experience in the area. For assessing the impact Arctic conditions will have on the time spent on maintenance tasks and the increased costs this implies based on the scarce statistical and experience data, Monte Carlo simulation can be a valuable tool.

Because of the lack of statistical data on environment factors and data on repair times for weather-exposed equipment in the Arctic, the case study in this paper will be based on assumptions, which will also be necessary in the early phases of production in Arctic areas. The factors presented will vary based on the geographical area and plant-specific variables. The consequences of longer repair and maintenance duration will be very different from equipment to equipment, from process equipment where the downtime can be very expensive to routine maintenance operations where the only cost will be the increased man-hours spent on the task.

This paper indentifies and discusses some influencing factors of the Arctic environment on the operation and maintenance of an offshore production facility. Moreover, this paper proposes a method for maintenance cost and time assessment by using Monte Carlo simulation method for uncertainty analysis which is to be used by a decision maker when designing for an offshore production facility to be used in the less familiar environment of the Arctic.

\section{Operation and Maintenance of an Offshore Production Facility under the Influencing Factors of Arctic Conditions}

Some of the factors influencing the operations in the Arctic include [7], [8], [9], [10], [11], [12], [13], [2] and will be further described in the following chapter.

\subsection{Arctic Climate}

The arctic operative environment is an extremely inhospitable environment that is characterized by extremely cold temperatures, high intensity and shifting winds, fog, darkness, icing, etc. These characteristics are further discussed below: 
- Low Temperatures: The Arctic areas are characterized by very low temperatures in most parts of the year. The average winter temperatures range from $0 \mathrm{C}^{\circ}$ to $-40 \mathrm{C}^{\circ}$ and the average summer temperatures range from $-10 \mathrm{C}^{\circ}$ to $+10 \mathrm{C}^{\circ}[14]$. In addition, there can be large temperature variations throughout the year.

- High Intensity Winds: The winds in Arctic areas can be very strong and can change direction quickly. The polar low pressure storms caused by hot southern air meeting cold Arctic air streams can cause sudden changes in wind direction and increase in wind intensity that is hard to model for meteorologists, and may result in unforeseen strong wind conditions.

- Foggy Conditions: The Arctic area is very susceptible to fog throughout the year. Burt (2007) [15] states that the Grand Banks off the shore of Newfoundland are considered to be the foggiest place on the earth with over 200 foggy days annually.

- Darkness: The Arctic regions experience extremes of solar radiation, with a total absence of sunlight in winter and sun the whole day in summer. Especially the absence of sunlight in the winter season can create bad working conditions.

- Icing: A challenge when the combined effects of low temperatures and high air humidity or low temperatures $\left(\mathrm{T}<10 \mathrm{C}^{\circ}\right)$ and strong wind cause spray blowing of the sea and freezing on the platform or ship superstructure. This has a potential of causing loss of stability and ice covering the hull and equipment.

- Ocean Temperature: Studies done by the Norwegian Polar Institute [16] show that the ocean temperatures in large parts of the Arctic and Sub-Arctic areas reach sub-zero temperatures in the winter time. This potentially increases strain on saltwater pumps, firewater systems and subsea equipment.

- Waves: The wave fetch are long in many Arctic areas - meaning the waves can gain more energy due to longer stretches of ocean [17]. In addition, the strong winds in the Arctic can further energize the waves that could result in high waves.

- Icebergs: Icebergs of varying size and shapes are found in different parts of the Arctic Ocean (see Kvitsrud, 1991 for details of icebergs [18]). These icebergs have a potential of creating large collision loads on the platforms as well as scouring of sea bottom structures in the shallow areas.

- Sea Ice: The Arctic Ocean is covered by ice cover in most of the seasons, the extent of ice cover varies from year to year. The ice cover poses a challenge to the vessel transportation to and fro from the offshore facilities in the Arctic Ocean. However, the damage potential from sea ice depends on the thickness of the ice cover, velocity of the ice and the size of the ice fields [18].

\subsection{Underdeveloped Infrastructure}

The Arctic areas are sparsely populated and generally the infrastructure is underdeveloped. This poses its own challenges for installation, operation and maintenance of facilities located in offshore areas. 
- Long Distances from Markets and Few Supply Bases: The distance to the suppliers and the market can be long resulting in long delivery times of supplies and spare parts.

- Shortage of Competence: Due to the sparse population, harsh conditions and the early phase of offshore production it can be a challenge to find and employ competent as well as experienced personnel in the arctic areas. Moreover, effort will be required to generate willingness amongst the competent and experienced personnel to work in the arctic conditions.

- Lack of Emergency Infrastructure: In the Arctic there is a shortage emergency infrastructure to contain the consequences of major accidents.

- Lack of Robust Weather Predictions: In the Arctic areas there are few weather stations and a limited statistical data to predict and make precise weather forecasts. Braset (2007) [19] states that statistical data from wind and wave measurements have their limitations due to the rapid changes in the climate experienced in the arctic areas.

- Political Issues: Preservation of environment in the arctic areas is a focus area in the government because of its vulnerability and pristine nature. The government regulations are stringent and the ambition is zero discharges and zero damage to environment. Wildlife protection and social cooperation with the groups of indigenous people are important. Failure in maintaining cordial relations has a potential of creating large impacts on the company's reputation.

Most of these factors will influence the design and the safe operations of the facilities. In the subsequent part of the paper, we will consider describe how these influencing factors will be modeled in the case study.

\subsection{Modeling the Influencing Factors}

To model the effect of the Arctic factors described in the previous chapter six parameters are identified, they are:

- Weather: Cold weather, strong winds, rain and snow slow down the work.

- Darkness: Darkness complicates the work and resupplying. This can be mitigated by the use of artificial light, but can still be a challenge.

- Sea Ice: Sea ice features delay operations and logistics, especially for operations where ROVs and divers are needed.

- Equipment Failure: Failures in tools, cranes, etc. can occur due to increased strains on hydraulic fluids, lower battery capacities and larger risk of human failures due to harsh conditions.

- Delays in Parts/Personnel Delivery due to Weather and Infrastructure: Delivery of parts/crew needed for the operations that are not stored/stationed on the platform can be delayed due to poor infrastructure and bad weather.

- Delays in Parts/Personnel Delivery due to Sea Ice: Delivery of parts/crew not stored/stationed on the platform can be delayed due to sea ice features.

However, for the equipment which is sheltered or placed indoors, the weather will not have any effect on the task itself, and the same conditions as on the Norwegian 
Continental Shelf can be expected, but delivery of parts and competent personnel can still be a problem. Sea ice will only be a problem in certain geographical areas; climatic conditions will vary a lot based on the season and geographical location of the installation. Even though industries such as mining, shipbuilding and onshore oil and gas production are well known and important in the Arctic region, and offshore exploration started several decades ago, only a few offshore production facilities have been built and put into production.

There is less experience from operations in these areas, and statistical data obtained from the Norwegian Continental Shelf may not be directly applicable for the Arctic [20], [21], [22], [23], and [24]. Also, based on the findings in a study by Homlong, an increase in failure rates and man-hours can be expected in the Arctic compared to more temperate areas [7], [9]. The model presented in this paper gives a tool that can help engineers, decision makers and planners make more realistic estimates of the man-hours used on operations and maintenance in Arctic areas through playing with different scenarios and equipment.

Gao presented a model in which production performance under Arctic conditions is predicted [20], [21], and [22]. The model presented in this paper is an alternative approach, where values are assigned directly to failure rates and climatic conditions to make it easier to implement and update data as more experience and statistical data is obtained. In the following chapter, a case for a specific seawater lift pump will be presented.

\section{A Seawater Lift Pump to Be Operated on a Floating Production Facility in the Southern Part of the Barents Sea: An Example}

Based on the research conducted on Arctic conditions a case study and model is developed to estimate the increases in man-hours and costs that can be expected in Arctic areas due to the differences in conditions from the NCS. The Monte Carlo simulation method will be used to give time and cost assessments for operations and maintenance. This method is useful in modeling phenomena with significant uncertainties in the input. The method relies on random sampling to compute the results. A series of discrete random events is established to generate a probability distribution [25]. This method is a more certain tool than many other alternative methods or human intuition and can give valuable information for both the design of the platform, maintenance planning, spare part logistics and for general operation because it gives probability distributions based on the identified parameters. The assigned parameters in the simulation can easily be updated as more statistical and experience data are obtained to give stronger results. The software Crystal Ball is used in the case study. Oracle Crystal Ball is a spreadsheet-based application for Monte Carlo simulations, risk measurement and reporting and time-series forecasting and optimization [26].

An annual flow test of the seawater lift pumps conducted in early spring show that one of the pumps has been damaged during the winter season and has lost much of its 
capacity, causing the need for a corrective repair of the pump. The pulling of the pump is expected to be an extensive operation on this platform where external experts have to be present. The time estimate for a similar setup on the Norwegian Continental Shelf is 168 hours for pulling the pump and 168 hours for placing a spare. Based on these experience data from the task on the NCS and data on Arctic factors a set of assumptions is made. These assumptions are assigned different probability distributions to give an estimate on the delays and increased man-hours that can be expected for the replacement or repair of the pump.

Table 1. Assumed increase in man-hours due to Arctic conditions

\begin{tabular}{|c|c|c|c|c|c|c|c|c|c|}
\hline & $\begin{array}{c}\text { Increase in } \\
\text { manhours (\%) }\end{array}$ & Mean $(\%)$ & $\begin{array}{c}\text { Median } \\
(\%)\end{array}$ & $\begin{array}{c}\text { Correlate } \\
d \text { to }\end{array}$ & $\begin{array}{c}\text { Correlation } \\
(\%)\end{array}$ & $\begin{array}{c}\text { Min } \\
(\mathrm{hrs})\end{array}$ & $\begin{array}{l}\text { Mean } \\
\text { (hrs) }\end{array}$ & $\begin{array}{c}\text { Median } \\
\text { (hrs) }\end{array}$ & Max (hrs \\
\hline \multicolumn{10}{|l|}{$\begin{array}{c}\text { Task: Pulling of seawater lift } \\
\text { pump }\end{array}$} \\
\hline Estimated manhours NCS & & & & & & & 336 & & \\
\hline Weather & $0-30 \%$ & $18 \%$ & $20 \%$ & & & 0 & 61 & 67 & 101 \\
\hline Darkness & $0-5 \%$ & $3 \%$ & $3,5 \%$ & Weather & $50 \%$ & 0 & 10 & 12 & 17 \\
\hline Machine failures & $0-10 \%$ & $5 \%$ & $5 \%$ & Weather & $80 \%$ & 0 & 17 & 17 & 34 \\
\hline Delivery of supplies, weather & $0-300 \%$ & $11 \%$ & $7,5 \%$ & Weather & $80 \%$ & 0 & 37 & 25 & 1008 \\
\hline Sea ice & $0 \%$ & $0 \%$ & $0 \%$ & & & 0 & 0 & 0 & 0 \\
\hline Delivery of supplies, sea ice & $0 \%$ & $0 \%$ & $0 \%$ & Sea ice & $90 \%$ & 0 & 0 & 0 & 0 \\
\hline Forecast, additional manhours & & & & & & 0 & 125 & 121 & 1160 \\
\hline
\end{tabular}

The table shows the minimum, mean and maximum addition to man-hours assumed for the task in Arctic conditions. The mean values are set for all the factors except for the "delivery of supplies, weather" where the median value is set. The minimum values are calculated with the formula below; the max values are calculated by changing the minimum percentage values for increase in man-hours with the maximum percentage value.

$\mathrm{FCA} \min (\mathrm{hrs})=\Sigma((\mathrm{W}(\min \%) \mathrm{x} \mathrm{ENCS})+(\mathrm{D}(\min \%) \mathrm{x} \mathrm{ENCS})+(\mathrm{MF}(\min \%) \mathrm{x}$ $\mathrm{ENCS})+(\mathrm{DSW}(\min \%) \times \mathrm{ENCS})+(\mathrm{SI}(\min \%) \times \mathrm{ENCS})+(\mathrm{DSI}(\min \%) \times \mathrm{ENCS}))$

Where FCA $\min (\%)$ is the smallest increase in forecasted additional man-hours (\%) defined in the assumption and ENCS is estimated man-hours for the NCS. The other abbreviations are: $\mathrm{W}$ is weather, $\mathrm{D}$ is darkness, MF is machine failures, DSW is delivery of supplies, weather, SI is sea ice and DSI is delivery of supplies, sea ice. The input distributions for the case study are:

- Weather

- Darkness

- Equipment failure

- Delayed delivery of spare parts and specialists due to bad weather and infrastructure

- Delay on delivery of spare parts/personnel due to sea ice

Sea ice is not considered in this scenario because it is not considered a problem for the Southern Barents Sea in this season. 
Weather: The transition between winter and spring is a period where harsh weather can be experienced in the Barents Sea with low temperatures, storms and blizzards. The operation considered in the case study is weather-sensitive. The weather delays are modeled as a triangular distribution with assigned values from 0-101 (0-30\%) for increase in man-hours, with the likeliest value of 61 hours (18\%) as shown in Fig. 1.

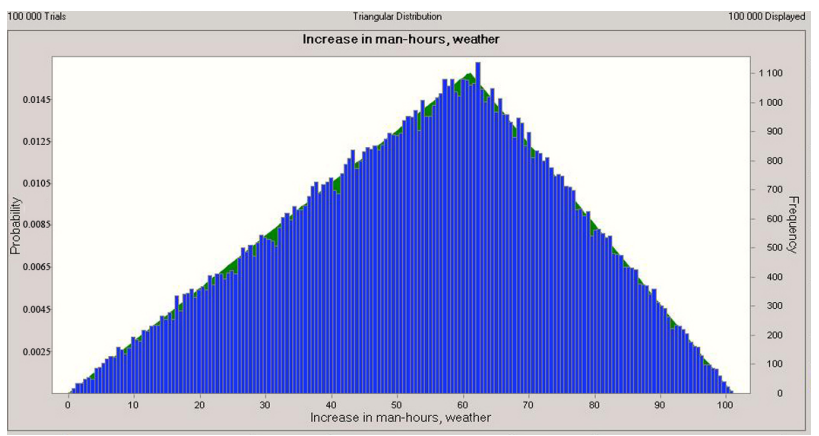

Fig. 1. Triangular distribution of increase in man-hours due to weather

Darkness: Early spring in the Barents Sea means that there is little daylight. It is modeled as a triangular distribution, assigned with the value $0-17$ hours $(0-5 \%)$ with the likeliest value of a 10-hour (3\%) increase because of strain on personnel, areas without proper lighting, etc. as shown in Fig. 2. This value is correlated by $50 \%$ to the weather values because the darkness increases with cloud coverage etc.

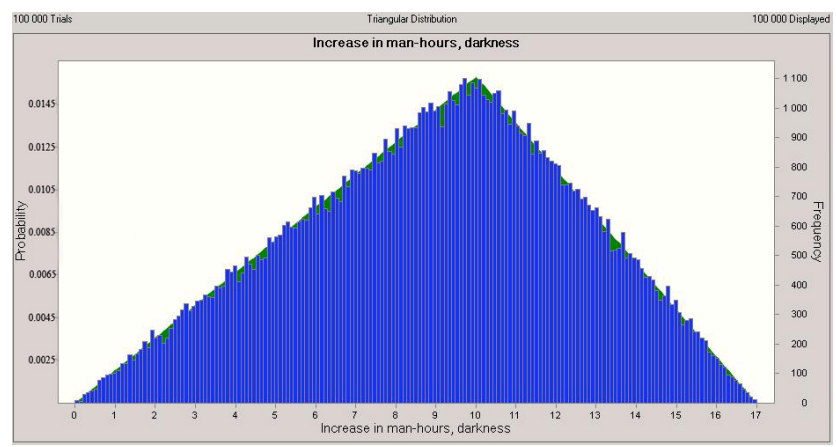

Fig. 2. Triangular distribution of increase in man-hours due to darkness

Equipment Failure: Failures in tools and equipment are modeled as a triangular distribution with the values 0-34 (0-10\%) increase in work-hours with the likeliest value of 17 hours (5\%) as shown in Fig. 3. This factor will be $80 \%$ correlated to the weather factor because in good weather the strains on equipment and personnel will be similar to the NCS and the same failure modes and frequencies can be expected. 


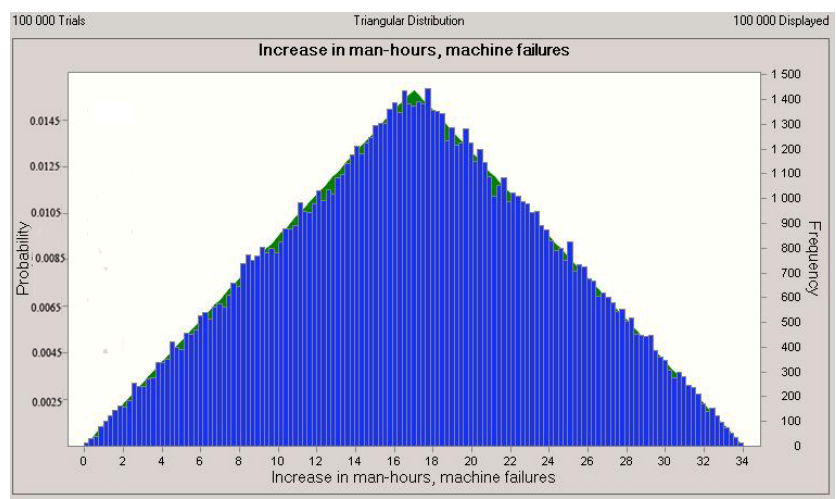

Fig. 3. Triangular distribution of increase in man-hours due to equipment failure

Delivery of Spare Parts and Specialists due to Bad Weather and Infrastructure: This factor is gamma distributed and assigned values from 0-1,008 hours (0-300\%) with a median value of 25 hours as shown in Fig. 4. It is assumed that a spare pump is stored on the platform, but other necessary parts, tools and experts might be delayed. This factor is considered weather-sensitive and $80 \%$ correlated with the weather factor. The $300 \%$ delay will be very rare, caused by long storm periods, equipment deliveries over long distances by truck, etc. The largest uncertainty in the simulation is found in this distribution; it has a variance of 1,488 hours due to the uncertainty in data. The Gamma distribution for the supply delays from weather gives very low chances for delays over 200 hours; this is due to difficulties in making distributions with the likeliest value much lower than the maximum value. If statistical data on weather can be obtained, this problem can be mitigated by making discrete probability distributions based on the weather observations.

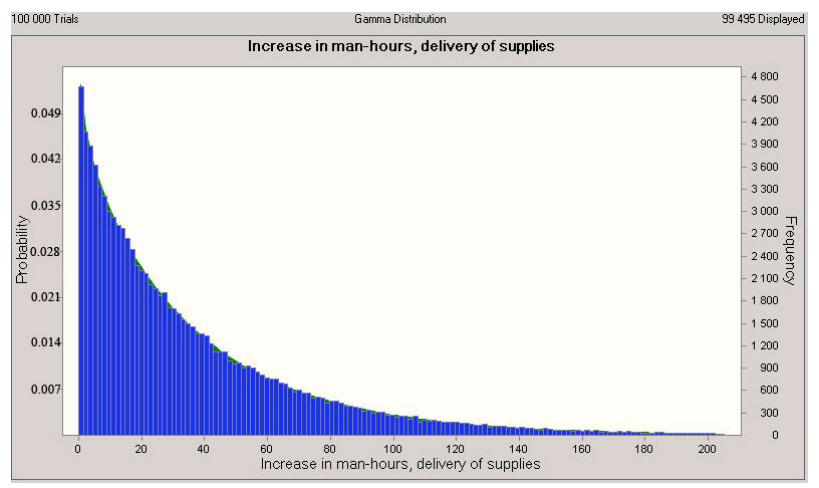

Fig. 4. Gamma distribution of increase in man-hours due to delays caused by weather and poor infrastructure 
Delay on Delivery of Spare Parts/Personnel due to Sea Ice: This factor is assigned the value $0 \%$ in this case because ice features are not expected in the Southern Barents Sea in this season.

Based on the probability distributions described, a Monte Carlo simulation with 100,000 trials is run, giving the gamma distribution shown in Fig. 5. The distribution has a mean increase in man-hours of 117 hours with a variance of 4,005 hours. The large variance illustrates that there are large uncertainties in the estimate. However, this will get better when more data on the input distributions are gained from experience and analyses. In spite of the large uncertainties, the model gives reason to believe that for this operation there will be an increase in man-hours due to Arctic conditions.

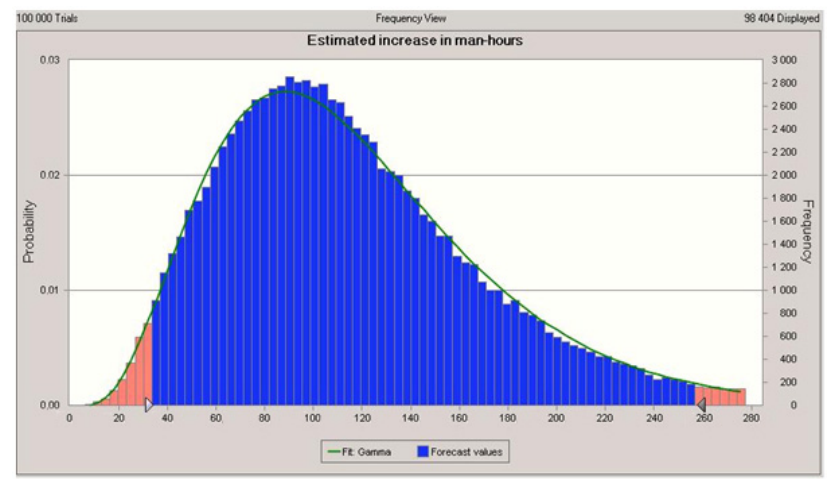

Fig. 5. Estimated increase in man-hours

By using Fig. 5, a probability of 50\% of delays between 75 and 140 hours is identified. To find the economic consequence of this delay, the price pr. man-hour is analyzed; for this case, where there is no production downtime, this will be solely the price pr. hour pr. worker. In this case, it is assumed that the price pr. man-hour pr. external specialist is $650 \mathrm{NOK}$. This assumption gives a $50 \%$ chance that the increase in costs for this task is between 48,750 NOK and 91,000 NOK (22-41\% increase in costs). The mean time increase identified in the model will be 117 hours $(34 \%)$ meaning a cost increase of 76,050 NOK. If the worst-case scenario defined in the assumption happens, the delay will be 1160 hours, meaning a cost increase of 754,000 $(345 \%)$. Based on this model, the chance of this is negligible.

\section{$4 \quad$ Concluding Remarks}

Based on the example and results presented and discussed in this paper, we can conclude that the Arctic climate can have a significant influence on the time and cost of the maintenance of offshore production facilities in the less familiar environment of the Arctic. Furthermore, lack of experience and statistical data might give large uncertainties in estimates and result in higher operational expenditures. The method presented in this paper can be used in maintenance time and cost assessment or when 
designing for operation and maintenance in order to provide more realistic cost and time estimates. As more experience and statistical data can be obtained, the method can be adjusted and optimized.

\section{References}

1. U.S. Geological Survey: Fact sheet; USGS Arctic Oil and Gas Report: Estimates of Undiscovered Oil and Gas North of the Arctic Circle (2008),

http: //geology.com/usgs/arctic-oil-and-gas-report.shtml

2. Freitag, D.R., McFadden, T.: Introduction to Cold Region Engineering. ASCE Press, Reston (1997)

3. Holmer, I., Granber, P., Dahlstrom, G.: Cold environments and cold work (2010), http://www.ilo.org/safework_bookshelf/english? content\&nd=857 170522

4. Gudmestad, O.T., Løset, S., Alhimenko, A.L., Shkinek, K.N., Tørum, A., Jensen, A.: Engineering aspects related to arctic offshore developments. LAN Publishing House, ST. Petersburg (2007)

5. Markeset, T.: Design for Production Performance in Arctic Locations Considering Maintenance and Support Services. In: The Proceedings of the Mine Planning and Equipment Conference (MPE 2008), Beijing, China (October 2008)

6. OREDA: Offshore Reliability Data, 5th edn. Topside Equipment, vol. 1. SINTEF Technology and Society, Trondheim (2009)

7. Homlong, E., Panesar, S.S., Markeset, T., Kumar, R.: Influence of Arctic Environment on Reliability, Availability, Maintainability and Supportability. In: The Proceedings of the COMADEM 2011 Conference, Stavanger, Norway (May 2011)

8. Linnè, A., Juntti, U.: Improving Conditions for Personnel Performing Condition Based Maintenance on Infrastructure by Measuring/Monitoring Their Winter Performance Ability. In: The Proceedings of the COMADEM 2011 Conference, Stavanger, Norway (May 2011)

9. Homlong, E.: Reliability, Availability, Maintainability and Supportability factors in an Arctic offshore operating environment: Issues and challenges. Master thesis, University of Stavanger, Stavanger, Norway (2010)

10. Larsen, A.C., Markeset, T.: Mapping of Operations, Maintenance and Support Design Factors in Arctic Environments. In: The Proceedings of the European Safety and Reliability Conference (ESREL 2007), Stavanger, Norway (June 2007) ISBN 978-0-415-44786-7

11. Markeset, T.: Design for High Performance Assurance for Offshore Production Facilities in Remote Harsh and Sensitive Environment. Quarterly Journal of the Operational Research Society of India, OPSEARCH 45(3), 275-290 (2008)

12. Markeset, T.: Design for Petroleum Production Performance in Arctic Locations Considering Maintenance and Support Services. In: The Proceedings of the Mine Planning and Equipment Selection Conference (MPES 2008), Beijing, China (October 2008)

13. Gudmestad, O.T., Zolothukhin, A.B., Ermakov, A.I., Jacobsen, R.A., Michtchenko, I.T., Vovk, V.S., Løset, S., Shkinek, K.N.: Basic of offshore petroleum engineering and development of marine facilities with emphasis on the Arctic offshore (1999) ISBN 5-72460100-1

14. Serreze, M., Roger, B.: The Arctic Climate System, 385 p. Cambridge University Press, New York (2005)

15. Burt, C.: Extreme Weather a guide \& record book. Norton, NY (2007) 
16. Søreide, E.J., Hop, H., Falk-Petersen, S., Gulliksen, B., Hansen, E.: Macrozooplankton communities and environmental variables in the Barents Sea marginal ice zone in late winter and spring. Norwegian Polar Institute, Troms $\emptyset$, Norway (2003)

17. Norwegian Centre of Expertise Instrumentation (NCEI), http://Barentssea.no (accessed February 15, 2010)

18. Kvitsrud, A.: Environmental Conditions in the Southern Barents Sea (1991), http://home.c2i.net/kvitrud/Arne/Environmental-condtionsBarents-Sea.htm (accessed February 20, 2011)

19. Braset, E.:: Evaluering av de fysiske forhold på boredekk og I boretårn ved operasjoner I arktiske Atlanterhavet med spesiell oppmerksomhet mot effektene vind og lave temperaturer skaper. MSc thesis, University of Stavanger, Norway (2007)

20. Gudmestad, O.T., Løset, S., Alhimenko, A.L., Shkinek, K.N., Tørum, A., Jensen, A.: Engineering aspects related to arctic offshore developments. LAN Publishing House, ST. Petersburg (2007)

21. Gao, X., Barabady, J., Tore Markeset, T.: Criticality Analysis of a Production Facility using Cost Importance Measures. International Journal of Systems Assurance Engineering and Management 1(1), 17-23 (2010)

22. Gao, X., Markeset, T., Barabady, J.: Design and Operational Maintainability Importance Measure - A Case Study. Quarterly Journal of the Operational Research Society of India, OPSEARCH 45(3), 189-208 (2008)

23. Barabadi, A., Markeset, T.: Reliability and Maintainability Performance under Arctic Conditions. International Journal of System Assurance Engineering and Management 2(2) (2011)

24. Barabadi, A., Barabady, J., Markeset, T.: Maintainability Analysis Considering TimeDependent and Time-Independent Covariates. Reliability Engineering \& System Safety 96(1), 210-217 (2011)

25. CSEP (Computational Science Education Project): Introduction to Monte Carlo Methods (1995), http: / / www . phy . ornl . gov/csep/CSEP/MC/MC . html

26. Oracle: Oracle Crystal Ball overview (2011), http://www.oracle.com/technetwork/middleware/crystalball/ overview/index.html 